\title{
Improving access in gastroenterology: The single point of entry model for referrals
}

\author{
Kerri L Novak MD MSc FRCPC ${ }^{1}$, Sander Veldhuyzen Van Zanten MD MSc MPH PhD², \\ Sachin R Pendharkar MD MSc FRCPC ${ }^{3}$
}

\begin{abstract}
KL Novak, S Veldhuyzen Van Zanten, SR Pendharkar. Improving access in gastroenterology: The single point of entry model for referrals. Can J Gastroenterol 2013;27(11):633-635.

In 2005, a group of academic gastroenterologists in Calgary (Alberta) adopted a centralized referral intake system known as central triage. This system provided a single point of entry model (SEM) for referrals rather than the traditional system of individual practitioners managing their own referrals and queues. The goal of central triage was to improve wait times and referral management. In 2008, a similar system was developed in Edmonton at the University of Alberta Hospital (Edmonton, Alberta). SEMs have subsequently been adopted by numerous subspecialties throughout Alberta. There are many benefits of SEMs including improved access and reduced wait times. Understanding and measuring complex patient flow systems is key to improving access, and centralized intake systems provide an opportunity to better understand total demand and system bottlenecks. This knowledge is particularly important for specialties such as gastroenterology (GI), in which demand exceeds supply. While it is anticipated that SEMs will reduce wait times for GI care in Canada, the lack of sufficient resources to meet the demand for GI care necessitates additional strategies.
\end{abstract}

Key Words: Access; Central triage; Single point of entry model; Wait times

W ait times to access specialist care in Canada have increased dramatically over the past two decades, with as many as $2.5 \%$ of the population waiting for a therapeutic or diagnostic procedure in 2012 (1). In 2006, the Canadian Association of Gastroenterology Wait Times Consensus Group published maximal medically appropriate wait times for 24 key areas of gastroenterology stratified according to acuity (2). However, wait times to see a gastroenterologist are not only in excess of these guidelines, but are increasing compared with 2005 (3-5). At one Canadian academic centre, wait times for endoscopic procedures also well beyond the recommendations, with $78.6 \%$ of patients experiencing delays that exceeded the targets from the consensus group (6). Patients are clearly affected: a Canadian survey of 916 patients awaiting gastrointestinal (GI) care showed that one-third believed that wait times were too long and $23 \%$ of them missed at least one day of work or school in the preceding month due to persistent GI symptoms (7). GI disease is common: $15 \%$ of health care costs in Canada were attributable to GI disease in 2001, exceeding the costs of many other common conditions (8). Additionally, the indirect costs to society related to untreated GI disease are significant $(9,10)$. Thus, targeted interventions to improve access for the diagnosis and treatment of GI disease are paramount.

The term 'triage' stems from the French word treir, meaning to sort. Triage in medicine refers to the prioritization of referrals based on urgency. Urgency, in turn, combines the severity of illness with the expected benefit of treatment and the natural history of the condition (11). Triage processes are often used when the demand for services exceeds the ability to provide them, compared with a balanced system in which patients are seen as they arrive, regardless of disease severity.

\section{Améliorer l'accès en gastroentérologie : le modèle du point d'entrée unique pour les aiguillages}

En 2005, un groupe de gastroentérologues universitaires de Calgary, en Alberta, a adopté un système centralisé d'admission des aiguillages, désigné de triage central. Ce système a fourni un modèle de point d'entrée unique (MEU) pour les aiguillages, en remplacement du système habituel de gestion des aiguillages et des listes d'attente par chaque praticien. Le triage central visait à améliorer les temps d'attente et la gestion des aiguillages. En 2008, un système similaire a été élaboré à la University of Alberta Hospital d'Edmonton, en Alberta. Les MEU ont ensuite été adoptés par plusieurs surspécialités de l'Alberta. Ils comportent de nombreux avantages, y compris un meilleur accès et une réduction des temps d'attente. Il est essentiel de comprendre et de mesurer les systèmes complexes d'acheminement des patients pour améliorer l'accès, et les systèmes d'admission centralisée permettent de mieux comprendre la demande totale et les engorgements du système. Ce savoir est particulièrement important dans des spécialités comme la gastroentérologie, où la demande est supérieure à l'offre. On prévoit que les MEU réduiront les temps d'attente en gastroentérologie au Canada, mais la pénurie de ressources nécessaires pour répondre à la demande en soins gastroentérologiques plaide en faveur de stratégies supplémentaires.

This type of systematized approach has existed for more than a century, with the first report of organized triage occurring in the 19th century on the battlefield with Napoleon's forces (12). Contemporary applications include care in emergency and surgical departments, as well as natural disasters and mass casualty incidents.

The notion of a single queue to reduce wait times for service has its roots in the field of operations management. Under a traditional 'multiple-queue, multiple-server' model, each physician's office has a separate queue. If a physician's appointment slots are full, a newly referred patient will wait for an appointment even if another physician has an available appointment slot. In contrast, when queues are combined, a newly referred patient can be scheduled into the next available appointment among a number of physicians. Consequently, the variability in wait times is reduced and the average wait for an appointment can also be decreased $(13,14)$.

There are several practical benefits of such a centralized intake system. The most important goal of the triage process is to ensure that the sickest patients are seen in the shortest time possible. With a single queue, the absence of appointment slots in one physician's clinic does not delay an appointment for the highest priority patient because patients can be scheduled into the next available slot among the other physicians participating in the centralized intake system. Centralized intake also makes it easier to ensure that supply and demand for more urgent cases is synchronized. Furthermore, the elimination of duplicate referrals reduces multiple physician appointments and may lower the frequency of cancelled or 'no-show' clinic or endoscopy slots. There is potential for cost saving and workload reduction through the use of nonphysician resources, such as nurses, to triage referrals, with

${ }^{1}$ Division of Gastroenterology, University of Calgary, Calgary; ${ }^{2}$ Division of Gastroenterology and AHS Zone Head Gastroenterology, Edmonton Zone,

Alberta, Edmonton; ${ }^{3}$ Medicine and Community Health Sciences at the University of Calgary, Calgary, Alberta

Correspondence: Dr Kerri L Novak, Division of Gastroenterology, University of Calgary, 3280 Hospital Drive Northwest, Calgary, Alberta T2N 4N1.

Telephone 403-592-5025, fax 403-592-5050, e-mail knovak@ucalgary.ca

Received for publication May 7, 2013. Accepted June 16, 2013 
physician oversight. Standardized guideline-based allocation of priority of referrals across physician's practices is facilitated, with quality assurance in the process and appropriateness of the referral and, potentially, the subsequent procedure. For example, wait times for screening colonoscopy can be significantly reduced when procedure indications strictly follow published surveillance guidelines (15).

Despite the numerous benefits, there are also many perceived drawbacks to the single point of entry model (SEM) that differ depending on the vantage point. Some gastroenterology physicians report a loss of 'control' of the triage of referrals and feel less ownership of the growing wait lists because they are not individually managed. There may be perceptions that relationships between referring physicians and specialists are depersonalized because referring physicians often develop special relationships with a limited number of specialists. In addition, the notion of 'cherry-picking' is a common concern, in which nonurgent cases may be distributed differently than the urgent and, potentially, more interesting cases. Referring physicians may regard SEM as a referral 'abyss' because the patient is not linked to a specific physician at the time of referral. This lack of trust of SEM is further exacerbated by a perceived lack of a physician-to-physician connection. Finally, administrators may be wary of upfront costs given the need for nursing and clerical staff to perform intake and triage duties, and additional significant costs associated with electronic referral management systems and the required monitoring of wait lists and wait times.

Some of the challenges in obtaining accurate wait times data may be overcome by the use of SEMs. To date, wait times data in gastroenterology are generated through physician practice audits and perceptions of wait times via patient surveys (2-6). This process is costly, labour intensive, vulnerable to reporting bias and typically represents a snapshot of access at a single point in time. Ideally, wait time measurements occur in conjunction with assessment of supply, outpatient clinic and endoscopy slots to determine whether supply meets the demand. Measures should include the availability of a sufficient number of slots for the required endoscopic procedures for referred patients. Accurate measurement of wait times (demand) and capacity is crucial for system and workforce planning. Accurate, prospective data reflecting referral demand may also help target specific diseases or populations, including populations requiring specialty services (eg, inflammatory bowel disease, screening colonoscopy, functional bowel disorders or motility). Using accurate data fluctuations in demand may become more predictable, which will help to improve the matching of demand with supply because supply-demand mismatch in the system is known to increase wait times (13). Regular reporting of wait time data can be used to engage gastroenterology consultants in the referral process and increase accountability to reduce wait times. From a quality perspective, centralized data collection can help ensure that prioritization policies are effective and improve the appropriateness of the requests $(15,16)$. Finally, there is the potential for greater transparency regarding access for the public and referring physicians.

\section{THE USE OF SEM IN CANADA}

An informal survey of sites across Canada revealed centralized triage processes are being increasingly adopted in academic centres. There are a number of sites in transition moving toward SEMs in combination with individual physician queues, while other sites have SEMs in development for targeted areas such as colon cancer screening. At many sites in Canada, most of the allocation of referral priority (triaging) is performed by individual gastroenterology consultants, with limited capacity to prospectively measure clinic or endoscopy wait times. Some centres and individual physicians stop accepting referrals after wait times exceed a given threshold given the inability to accommodate referrals in an acceptable time frame. Urgent cases across the country are accommodated as quickly as possible, and many centres have scheduled, reserved endoscopy slots for very urgent cases to be seen as soon as possible.

\section{SEM IN ALBERTA}

Central triage was established in 2005 at one academic site in Calgary (Alberta) and included 17 of 19 physicians. It has grown today to include 23 physicians based in three hospital sites. Triage occurs in accordance with best practice priority allocation guidelines established by the Canadian Association of Gastroenterology in 2006 (2). More than $50 \%$ of cases received are triaged by nurses, while more challenging and complex cases are triaged by rotating gastroenterologists. Although a standardized referral form exists, it is not universally used and the quality of referral information received varies widely. This is a universal challenge in specialty care (17). Primary care physicians are burdened by the requirement to complete separate referral forms for multiple specialty services, and are frustrated that referrals are routinely rejected due to a lack of complete or required information. These process inefficiencies further delay patient care. The most urgent patients (eg, progressive dysphagia, abnormal imaging to suggest malignancy) are directed to the physicians on call in a regularly scheduled slot for both consult and procedure if indicated. Referrals to a subspecialty service, such as endoscopic ultrasound, inflammatory bowel disease, hepatology, interventional gastroenterology and nutrition, are all directed through the SEM system to that subspecialty physician group. Referring physicians can specifically request a particular physician, but most patients are assigned to the next available physician in the group. Re-referrals are directed to the gastroenterologist who previously saw the patient within the past three years, otherwise they re-enter the queue in priority sequence.

In Calgary, Gastroenterology Central Triage receives approximately 1000 to 1400 referrals per month. Before the institution of a patient management system in September 2011, wait times to both clinic and endoscopy were calculated manually. With the implementation of an electronic referral tracking system, we now have more accurate estimates of wait times. The creation of dedicated urgent clinics and on-call endoscopy slots has reduced urgent wait times: in March 2012, the wait for an urgent clinic slot was nine weeks and more than one month for acute disease such as progressive dysphagia. Currently, urgent patients who are referred through SEM wait for less than two weeks for acute concerns and approximately four weeks to be seen in the urgent clinic. Given the fixed capacity and increasing referral intake, the routine waits continue to grow with those who are classified as routine currently waiting for approximately 18 to 24 months. In most centres, the limiting step or 'bottleneck' is assumed to be the availability of endoscopy slots; however, a clear evaluation of the complex patient flow pathways within gastroenterology practice in Calgary has not been performed. Thus, it is unclear whether the main source of congestion is endoscopy or clinic appointments.

A central triaging SEM was developed, tested and is currently in use at the University of Alberta Hospital in Edmonton. The system is very similar to the SEM used in Calgary. Referrals to luminal gastroenterology and hepatology reflect a wide spectrum of symptom complexes and diseases including urgent and routine requests. Patients are triaged according to acuity: emergent (less than two weeks), urgent (two to four weeks), semiurgent (four to eight weeks) and nonurgent (less than six months). However, similar to most other sites across the country, the demand for outpatient consultative services in Edmonton far exceeds supply; consequently, wait times are long and rejection rates substantial (18). The negative consequences for the care of patients who are rejected have been well documented and published in this Journal (19).

Private practice gastroenterologists in the Edmonton zone face similar challenges; however, data regarding wait times and rejection rates are not systematically collected. Importantly, an initiative is underway for the development and introduction of a provincial pathway for gastroenterology and hepatology referrals. This pathway has received broad input from stakeholders in family medicine, private practice and academic gastroenterologists, surgery and cancer care, reflecting urban and rural sites across Alberta. This system will be electronic, using 27 indications for referrals and triaging them according to acuity using the above-mentioned four triage categories. Hopefully, this system will lead to more uniformity in quality of referrals, with enhanced quality in triage and prioritization. This is particularly important for rural 
communities, given significant current challenges to access outpatient gastroenterology services in rural Alberta.

\section{INNOVATIONS TO IMPROVE ACCESS}

The establishment of an SEM in any centre will not solve all of the problems with access that we face in gastroenterology. One key challenge is the appropriateness of referrals, with decisions required as to whether referrals should be accepted, declined or directed toward other pathways. For example, in Calgary, requests for initial screening for Barrett's esophagus in individuals with longstanding, controlled, asymptomatic heartburn are often declined (in the absence of risk factors) given recently revised guidelines for Alberta (20). Strict adherence to the Canadian Association of Gastroenterology colorectal cancer screening guidelines is important to reduce unnecessary polyp surveillance $(15,21,22)$. Telephone consultation service can reduce inappropriate referrals and address management issues that may be resolved over the telephone, particularly in patients who have previously been assessed. Another innovation occurring at multiple sites across the country is a 'direct to procedure' pathway, in which patients with uncomplicated GI conditions (eg, progressive dysphagia) and no significant language or cognitive barriers are seen for a consultation and procedure in the endoscopy suite. Recent Canadian Association of Gastroenterology data demonstrate reduction in wait times for this stream compared with 2008 (5). In addition, pooling of endoscopy resources among physician groups has been shown to improve utilization in the United Kingdom (23).

Finally, there is potential to better utilize nurse-based clinical care and education as a strategy to improve clinic work-flow and patient throughput. A nurse-led, collaborative pathway with primary care in Calgary has been undertaken for the management of clearly defined symptoms (eg, reflux and dyspepsia). Patients directed to this pathway have an initial telephone consultation with a nurse clinician, followed by a group (up to eight patients per session) medical consultation with a primary care team including nutrition, pharmacy and behaviour change management, and a gastroenterology nurse and consultant. The goal of this pathway is to improve patient education, referring physician satisfaction and, ultimately, to reduce referrals for these conditions through greater support for primary care physicians.

\section{THE TAKE-HOME MESSAGE}

Increasingly, Canadian gastroenterologists will need to be accountable to patients, payers and one another, with objective and accurate measures of wait times and, thus, access to outpatient consultations and endoscopic procedures. Objective measures of patient access ('feelings are good but measurements are better') are key to lobby government for increased resources to ensure adequate 'supply' of physician and endoscopy resources. The SEM enables improved data collection and has demonstrated benefits in enhancing access. Although an initial investment is required, the SEM can ultimately reduce costs by avoiding referral duplication and reduction of inappropriate referrals. There is increased assurance that the sickest patients are seen first and target patient populations may be prioritized. Physician workload may be reduced, with nurse assignment of referral priority. Innovations within SEM to improve access can occur, including assurance of referral appropriateness for consultation and endoscopy, telephone consultations, development of specialized clinics, and streamlining pathways for patients with uncomplicated problems utilizing nurse-based education and support. Improving access to GI care in Canada is of paramount importance and, in the face of resource constraint, innovations to support patients, improve efficiencies and limit cost within the existing system are key to success.

ACKNOWLEDGEMENTS: The authors thank Drs Mark Swain and Don McIntosh for their insights and edits.

\section{REFERENCES}

1. Barua B, Rovere M, Skinner B. Waiting your turn: Wait times for health care in Canada, 2011 report. Fraser Institute. <www. fraserinstitute.org/ uploadedFiles/fraser-ca/Content/research-news/ research/publications/ waiting-your-turn-2011.pdf>

(Accessed June 3, 2013).

2. Paterson W, Depew W, Pare P, et al. Canadian consensus on medically acceptable wait times for digestive health care. Can J Gastroenterol 2006;20:411-23.

3. Armstrong D, Barkun A, Chen Y et al. Access to Specialist Gastroenterology care in Canada: The practice audit in gastroenterology (PAGE) wait times program. Can J Gastroenterol 2008;22:155-60.

4. Leddin D, Bridges R, Morgan D, et al. Survey of access to Gastroenterology in Canada: The SAGE wait times program. Can J Gastroenterol 2010;24:20-5.

5. Leddin D, Armstrong D, Borgaonkar M, et al. The 2012 SAGE wait times program: Survey of Access to Gastroenterology in Canada. Can J Gastroenterol 2013;27:83-9.

6. Yu D, Hopman W, Paterson W. Wait time for endoscopic evaluation at a Canadian tertiary care centre: Comparison with Canadian Association of Gastroenterology targets. Can J Gastroenterol 2008;22:621-6.

7. Paterson W, Barkun A, Hopman W, et al. Wait times for gastroenterology consultation in Canada: The patient's perspective. Can J Gastroenterol 2010;24:28-32.

8. Beck I. Disproportion of economic impact, research achievements and research support in digestive disease in Canada. Clin Invest Med 2001;24:12-36.

9. Binion D, Louis E, Oldenburg B, et al. Effect of adalimumab on work productivity and indirect costs in moderate to severe Crohn's disease: A meta-analysis. Can J Gastroenterol 2011;25:492-6.

10. Bodger K. Cost of illness of Crohn's disease. Pharmacoeconomics 2002;20:639-52.

11. Hadorn D. Setting priorities for waiting lists: Defining our terms. CMAJ 2000;163:857-60.

12. Mitchell G. A brief history of triage. Disaster Med Public Health Prep 2008;2(Suppl 1):S4-S7.

13. Palvannan RK, Teow KL. Queueing for healthcare. J Med Syst 2012;36:541-7.

14. Bungard T, Smigorowsky M, Lalonde L, et al. Cardiac EASE (Ensuring Access and Speedy Evaluation) - the impact of a singlepoint-of-entry multidisciplinary outpatient cardiology consultation program on wait times in Canada. Can J Cardiol 2009;25:697-702.

15. Chivers K, Basnyat P Tafinder N. The impact of national guidelines on the waiting list for colonoscopy: A quantitative clinical audit. Colorectal Dis 2009;12:632-41.

16. Torkki M, Linna M, Seitsalo S, Paavolainen P. How to report and monitor performance of waiting list management. Int J Tech Assess Health Care 2002;18:611-8.

17. Akbari A, Mayhew A, Al-Alawi MA, et al. Interventions to improve outpatient referrals from primary care to secondary care. Cochrane Database Syt Rev 2008;8(4):CD005471.

18. Crespin M, Schreuders E, Veldhuyzen van Zanten S. Comparison of actual wait times of University of Alberta gastroenterology outpatients to published Canadian Association of Gastroenterology maximal acceptable wait times. Can J Gastroenterol 2011;25(SupplA):122A. (Abst)

19. de Boer EM, Pincock D, van Zanten SV. The 'natural history' of declined outpatient gastroenterology referrals. Can J Gastroenterol 2012;26:785-90.

20. Alberta Provincial Gastrointestinal Tumor Team. Management of early esophageal cancer, dysplastic and non-dysplastic Barrett's esophagus. Alberta Health Services Cancer Guidelines. <www.albertahealthservices.ca/cancerguidelines.asp> (Accessed February 2013).

21. Leddin D, Enns R, Hilsden R, et al. Canadian Association of Gastroenterology position statement on screening individuals at average risk for developing colorectal cancer: 2010. Can J Gastroenterol 2010;24:705-14.

22. Schreuders E, Sint Nicolaas J, de Jonge V, et al. The appropriateness of surveillance colonoscopy intervals after polypectomy. Can J Gastroenterol 2013;27:33-8.

23. Valori RM, Barton R, Johnston, DK. The English National Endoscopy Quality Assurance Programme: Quality of care improves as waits decline. Gastrointestinal Endosc 2009;69:AB221. (Abst) 


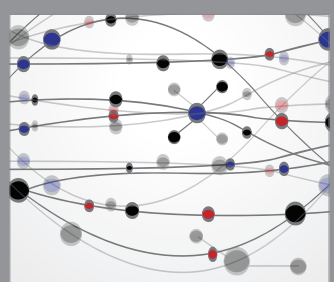

The Scientific World Journal
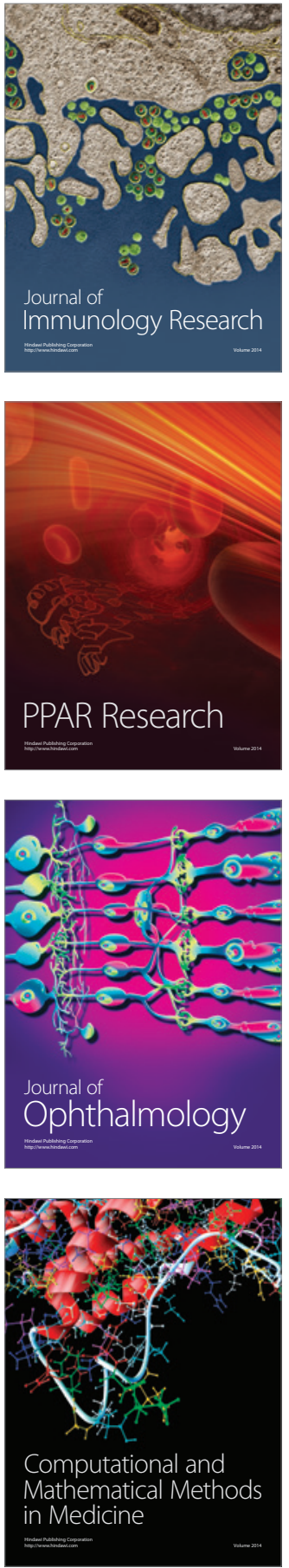

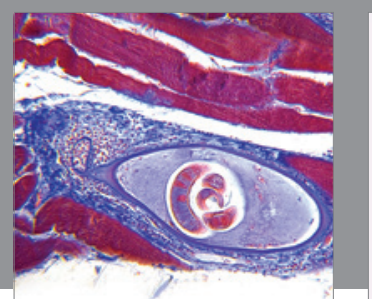

Gastroenterology Research and Practice

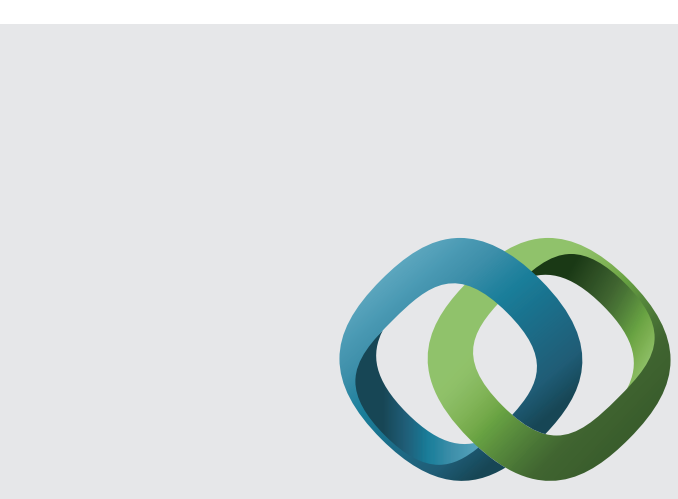

\section{Hindawi}

Submit your manuscripts at

http://www.hindawi.com
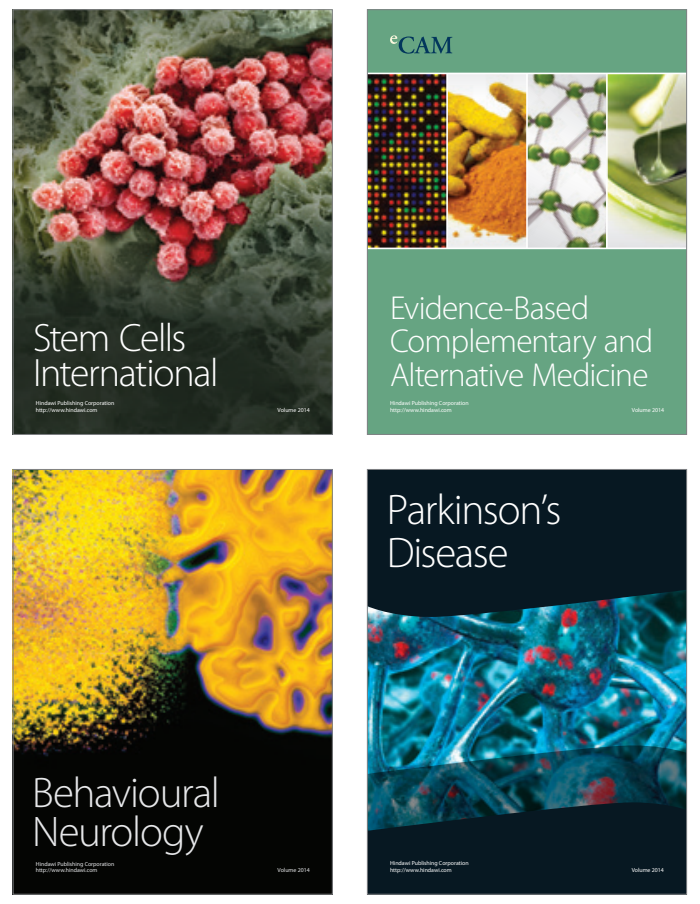
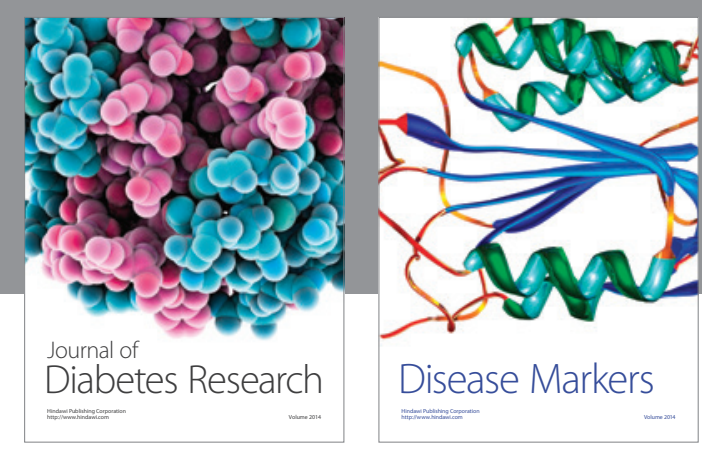

Disease Markers
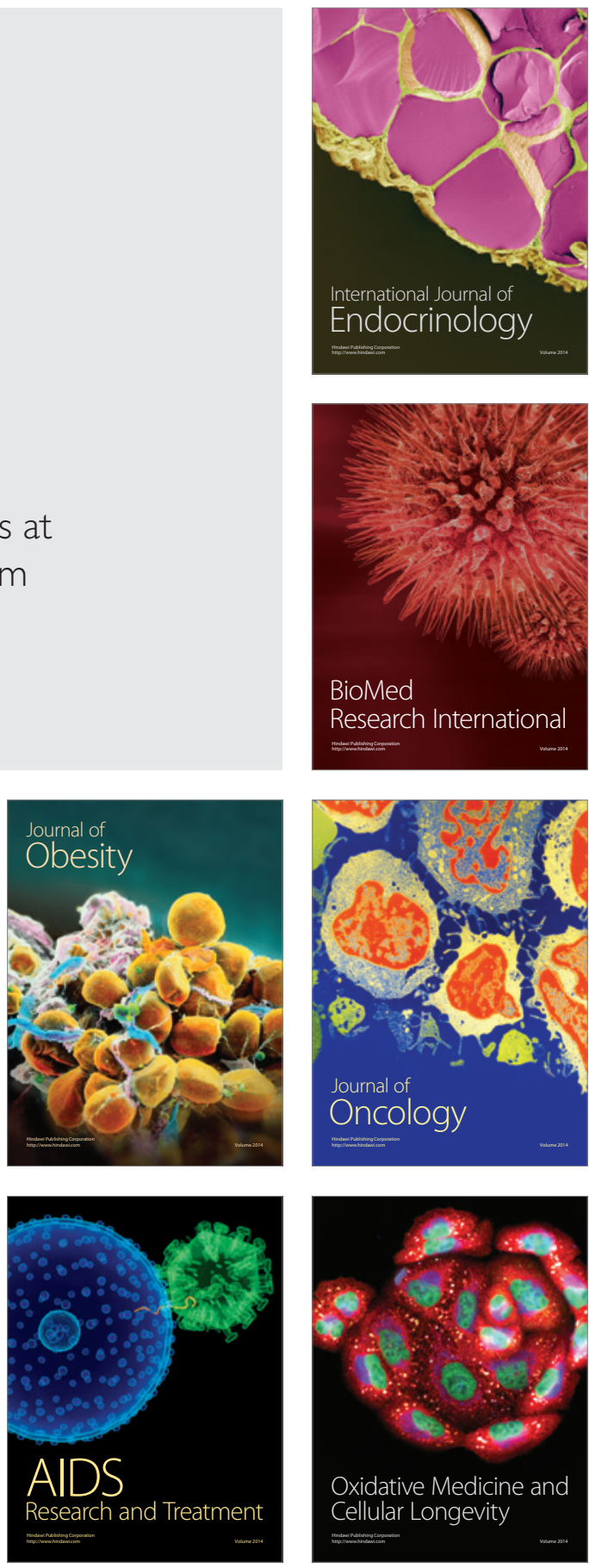